\title{
Practical Insights and Challenges in the Rational Use of Targeted Agents in Metastatic Clear Cell Renal Carcinoma
}

\author{
Swati Andhavarapu ${ }^{1} \&$ Winston W. Tan ${ }^{1}$ \\ ${ }^{1}$ Division of Hematology and Oncology, Mayo Clinic, Florida, USA \\ Correspondence: Winston W. Tan, Division of Hematology and Oncology, Mayo Clinic, 4500 San Pablo Road, \\ Jacksonville, Florida, USA-32224. Tel: 001-904-953-6153. Email: tan.winston@mayo.edu
}

Received: January 19, 2012 Accepted: February 5, 2012 Online Published: May 1, 2012

doi:10.5539/cco.v1n1p1

URL: http://dx.doi.org/10.5539/cco.v1n1p1

\begin{abstract}
Renal cell carcinoma (RCC) accounts for approximately 4\% of all primary cancers diagnosed in the United States with an estimated 13,000 deaths in 2010. Metastatic disease is the initial presentation in approximately $30 \%$ of the patients. Until 2006, immunotherapy with Interferon- $\alpha$ and Interleukin-2 represented the primary treatment of advanced RCC but better understanding of the pathogenesis and molecular biology of RCC paved the way for targeted molecular therapies. Six molecular targeted agents have been approved for the treatment of metastatic renal cell carcinoma (mRCC). This review summarizes the approved targeted agents, their toxicities and practical insights into the treatment of mRCC.
\end{abstract}

Keywords: metastatic renal cell carcinoma, molecular targeted agents, multikinase inhibitors, mTOR inhibitors, biomarkers, sequential therapy, future

\section{Introduction}

Renal cell carcinoma (RCC) accounts for approximately 4\% of all primary cancers diagnosed in the United States with an estimated 13,000 deaths in 2010 (Jemal, Siegel, Xu, \& Ward, 2010). Clear cell renal cell carcinoma represents $70-80 \%$ of the RCC and is typically characterized by malignant epithelial cells with clear cytoplasm arranged in sheets, acini, or alveoli with a prominent thin-walled vasculature (Jemal et al., 2010; Moch et al., 2000). Metastatic disease is the initial presentation in approximately $30 \%$ of the patients (Tsui et al., 2000). Until 2006, immunotherapy with Interferon- $\alpha$ and Interleukin-2 represented the primary treatment of advanced RCC. Both the agents demonstrated overall response rates of $10-20 \%$ but are associated with significant toxicity. Better understanding of the pathogenesis and molecular biology of RCC paved the way for targeted molecular therapies. Von Hippel-Lindau (VHL) mutations and loss of heterozygosity is observed in majority of clear cell RCC (Gnarra et al., 1994). When VHL gene function is lost, there is over expression of hypoxia responsive proteins such as vascular endothelial growth factor (VEGF) and platelet derived growth factor (PDGF) which promote angiogenesis and tumor cell growth (Kim \& Kaelin, 2004). Tumor angiogenesis is also stimulated by other growth factors that activate Akt and mammalian target of rapamycin (mTOR) signaling (Hudson et al., 2002). These pathways have emerged critical factors in the pathogenesis of RCC leading to the development of targeted agents (Mulders, 2009). Six molecular targeted agents have been approved for the treatment of metastatic renal cell carcinoma (mRCC).

\subsection{Immunotherapy}

Spontaneous regression of the metastatic disease following nephrectomy has been reported, albeit in low numbers suggesting an immunogenic nature of renal cell carcinoma (Gleave et al., 1998). Cellular effector mechanisms via cytotoxic $\mathrm{T}$ lymphocytes, natural killer cells (NK cells) and macrophages are considered important mediators in antitumor activity. Until 2006, immunotherapy with Interferon- $\alpha$ and Interleukin-2 represented the primary treatment of advanced RCC. While the mechanism of action of Interferon-alpha (IFN- $\alpha$ ) is not well understood, it is thought to stimulate cell mediated toxicity as well as have direct antitumor and antiangiogenic activity (Bleumer, Oosterwijk, De Mulder, \& Mulders, 2003). It demonstrated an overall response rate of $12 \%$ based on meta-analysis of 1042 patients with higher responses in patients with small volume disease that is primarily limited to the lung (Wirth, 1993).

Interleukin-2 (IL-2) is another cytokine with activity in renal cell carcinoma. It is produced by CD4+, CD8+ and large granular lymphocytes and is a major activator of $\mathrm{T}$ cells and macrophages. It stimulates secretion of several 
different cytokines like IFN- $\alpha$ and tumor necrosis factor which activates the monocyte-macrophage lineage thereby inducing differentiation of lymphokine-activated killer cells and antibody-dependent cell mediated toxicity (Bleumer et al., 2003). Therapy with Interleukin-2 (IL-2) results in similar response rates of 10-20\% with complete and durable responses in up to $10 \%$ in patients on high dose regimens (Yang, Sherry, et al., 2003; McDermott et al., 2005). However, both the agents are associated with significant toxicity and lower responses in second line setting after progression on the other cytokine (eg, IFN- $\alpha$ following IL-2) leading to quest for better agents (Escudier et al., 1999).

\section{Molecular-Targeted Agents for mRCC}

Chemotherapy had been used for many years with very poor response rates. Better understanding of the molecular biology of RCC paved the way for development of targeted therapies. The molecular-targeted agents approved for the treatment of metastatic renal cell carcinoma are sorafenib, sunitinib, bevacizumab (in combination with IFN- $\alpha$ ), temsirolimus, everolimus and pazopanib (Table 1). The targeted agents can be broadly placed under three categories-multikinase inhibitors, VEGF inhibitor and mTOR inhibitors:

Table 1. Efficacy and toxicities of the approved molecular targeted agents

\begin{tabular}{|c|c|c|c|c|}
\hline & ORR (\%) & $\begin{array}{l}\text { PFS } \\
\text { (months) }\end{array}$ & $\begin{array}{l}\text { OS } \\
\text { (months) }\end{array}$ & $\begin{array}{l}\text { Toxicities (common and major } \\
\text { AEs) }\end{array}$ \\
\hline \multicolumn{5}{|l|}{ First line therapy } \\
\hline $\begin{array}{l}\text { Sunitinib vs IFN- } \alpha \\
\text { (Escudier, Roigas, et al., } \\
\text { 2009) }\end{array}$ & $\begin{array}{l}31 \text { vs } 6 \\
(p<0.001)\end{array}$ & $\begin{array}{l}11.0 \text { vs } 5.0 \\
(p<0.001)\end{array}$ & $\begin{array}{l}26.4 \text { vs } \\
21.8\end{array}$ & $\begin{array}{l}\text { Fatigue, diarrhea hypertension } \\
\text { vomiting, HFS decreased LVEF }\end{array}$ \\
\hline $\begin{array}{l}\text { Bevacizumab+IFN vs IFN } \\
\text { (AVOREN) (Escudier et al., } \\
\text { 2010) }\end{array}$ & $\begin{array}{l}31 \text { vs } 13 \\
(p<0.001)\end{array}$ & $\begin{array}{l}10.2 \text { vs } 5.4 \\
(p<0.001)\end{array}$ & $\begin{array}{l}23.3 \text { vs } \\
21.3\end{array}$ & $\begin{array}{l}\text { Fatigue, asthenia hypertension, } \\
\text { proteinuria, VTE bleeding }\end{array}$ \\
\hline $\begin{array}{l}\text { Bevacizumab+IFN vs IFN } \\
\text { (CALGB 90206) (Rini et } \\
\text { al., 2010) }\end{array}$ & $\begin{array}{l}25.5 \mathrm{vs} \\
13.1\end{array}$ & $\begin{array}{l}8.5 \text { vs } 5.2 \\
(p<0.0001)\end{array}$ & $\begin{array}{l}18.3 \mathrm{vs} \\
17.4\end{array}$ & $\begin{array}{l}\text { Hypertension, anorexia, fatigue } \\
\text { Proteinuria }\end{array}$ \\
\hline $\begin{array}{l}\text { Pazopanib vs placebo } \\
\text { (Sternberg et al., 2010) }\end{array}$ & $\begin{array}{l}30 \text { vs } 3 \\
(p<0.0001)\end{array}$ & $\begin{array}{l}9.2 \text { vs } 4.2 \\
(p<0.0001)\end{array}$ & not mature & $\begin{array}{l}\text { Diarrhea, nausea vomiting, } \\
\text { anorexia hair color changes }\end{array}$ \\
\hline $\begin{array}{l}\text { Temsirolimus vs IFN vs } \\
\text { Temsirolimus+IFN } \\
\text { (Hudes et al., 2007) }\end{array}$ & $\begin{array}{l}8.6 \text { vs } 4.8 \\
\text { vs } 8.1\end{array}$ & $\begin{array}{l}5.5 \text { vs } 3.1 \text { vs } \\
4.7\end{array}$ & $\begin{array}{l}10.9 \text { vs } 7.3 \\
\text { vs } 8.4 \\
\text { months }\end{array}$ & $\begin{array}{l}\text { Rash, peripheral edema, } \\
\text { asthenia, hyperglycemia, } \\
\text { hyperlipidemia }\end{array}$ \\
\hline \multicolumn{5}{|l|}{ Second line therapy } \\
\hline $\begin{array}{l}\text { Sorafenib vs placebo } \\
\text { (Escudier, Eisen, et al., } \\
\text { 2009) }\end{array}$ & 57 vs 34 & $\begin{array}{l}5.5 \text { vs } 2.8 \\
(p<0.000001 \\
)\end{array}$ & $\begin{array}{l}17.8 \text { vs } \\
14.3\end{array}$ & $\begin{array}{l}\text { Cardiotoxicity HFS, bleeding } \\
\text { Fatigue, rash, Hypertension }\end{array}$ \\
\hline $\begin{array}{l}\text { Everolimus vs placebo (R. J. } \\
\text { Motzer et al., 2010) }\end{array}$ & $\begin{array}{l}66.8 \text { vs } \\
32.4\end{array}$ & $\begin{array}{l}4.9 \text { vs } 1.9 \\
(p<0.001)\end{array}$ & 10.0 vs 4.8 & $\begin{array}{l}\text { Stomatitis, Infections, fatigue, } \\
\text { Dyspnea, diarrhea, } \\
\text { Pneumonitis, Elevated LFTs }\end{array}$ \\
\hline $\begin{array}{l}\text { ORR: overall response rate; } \mathrm{P} \\
\text { IFN: interferon; HFS: hand-fo } \\
\text { thromboembolism; AVOREN } \\
\text { Leukemia Group B; LFTs: liv }\end{array}$ & FS: progressi & $\mathrm{n}$ free survival; & OS: overall st & $\begin{array}{l}\text { rvival; AE: adverse event } \\
\text { fraction; VTE: venous } \\
\text { ma; CALGB: Cancer and }\end{array}$ \\
\hline
\end{tabular}




\subsection{Multikinase Inhibitors}

\subsubsection{Sorafenib}

Sorafenib (BAY 43-9006) was the first targeted agent approved for treatment of patients with cytokine refractory advanced RCC or mRCC. It is an oral multikinase inhibitor that targets receptor tyrosine kinases (RTK) including VEGF receptors (VEGFR), platelet derived growth factor receptors (PDGFR), FMS-like tyrosine kinase 3 (FLT-3) and RET (Brugarolas, 2007).

Encouraging results from a phase II randomized discontinuation trial comparing sorafenib to placebo (Ratain et al., 2006) led to a phase III randomized Treatment Approaches in RCC Global Evaluation Trial (TARGET) study eventually leading to its approval (Escudier et al., 2007). 903 patients with cytokine refractory mRCC were randomly assigned to sorafenib (400 mg twice daily) and placebo administered in 6-week cycles for the first 24 weeks and in 8-week cycles thereafter till evidence of disease progression or patient withdrawal from the study. Analysis of median progression free survival (PFS) showed a statistically significant benefit in the sorafenib arm (5.5 months vs 2.8 months in the placebo group; $\mathrm{p}<0.01$ ) as a result of which crossover was offered to the placebo group. In the final analysis, the median overall survival was comparable in both arms (17.8 vs 15.2 months in placebo arm, $\mathrm{p}=0.146$ ). However, when post-cross-over placebo survival data was censored, survival advantage was demonstrated in patients who received sorafenib (17.8 $\mathrm{v} 14.3$ months, $\mathrm{p}=0.0287)$ (Escudier, Eisen, et al., 2009).

Another randomized phase II trial tested sorafenib (400 mg twice daily) in first line setting in comparison to interferon $\alpha-2 \mathrm{a}$ in patients with mRCC (Escudier, Szczylik, et al., 2009). The PFS for sorafenib and IFN-2 $\alpha$ treatment arms were similar in both the arms (5.6 vs 5.7 months). Sorafenib-treated patients experienced better quality of life and tumor reductions. Patients who progressed on sorafenib underwent dose escalation to $600 \mathrm{mg}$ twice daily; interferon $\alpha$-2a patients who progressed were switched to sorafenib arm (400 $\mathrm{mg}$ twice daily). Among patients who received escalated doses of sorafenib (600 mg twice daily), $42 \%$ experienced tumor reduction and better quality of life with median PFS of 3.6 months. There was no increase in grade 3 or more adverse events (AEs) after sorafenib dose escalation. $76 \%$ of patients who switched from IFN- $\alpha$ to sorafenib demonstrated reduction in tumor volume (median PFS of 5.3 months) suggesting clinical benefit of first line sorafenib compared with IFN $\alpha-2 a$. The PFS observed in the study was lower than expected (earlier results showed median PFS rates between 5.7 and 10 months) and was attributed to less favorable prognostic features in the study population. There was however, a positive trend of PFS in patients with liver and bone metastases. The study showed not only the clinical utility of sorafenib after IFN- $\alpha-2$ a failure, but also the possibility for sorafenib as a practical alternative to first-line IFN- $\alpha-2 \mathrm{a}$ in selected patients (Escudier, Szczylik, et al., 2009).

\subsubsection{Sunitinib}

Sunitinib (SU11248) is an oral broad spectrum receptor tyrosine kinase inhibitor (RTKI) that inhibits signaling by VEGFRs, PDGFRs, FLT-3 and c-Kit (Brugarolas, 2007). It was approved for second line therapy of mRCC based on response rates seen in two phase II trials (R. J. Motzer, Michaelson, et al., 2006; R. J. Motzer, Rini, et al., 2006). A pooled analysis of the two trials $(\mathrm{n}=168)$ showed $42 \%$ response rate ( 71 patients) with stabilization of the disease for 3 or more months in $24 \%$ of the patients. The median PFS was 8.2 months for all patients and 14.8 months in patients who achieved complete or partial response (CR/PR) (R. J. Motzer, Rini, et al., 2006).

The efficacy and tolerability profile of sunitinib observed in second-line setting in $\mathrm{mRCC}$ led to a phase III trial of sunitinib versus interferon- $\alpha$ in previously untreated mRCC patients (R. J. Motzer et al., 2007). 750 patients were randomized to receive either repeated 6 -week cycles of sunitinib at a dose of $50 \mathrm{mg}$ orally once daily for 4 weeks, followed by 2 weeks without treatment (4/2) or interferon-alfa at a dose of 9 million units (MU) subcutaneously thrice weekly (escalated in weekly increments from 3 to 6 to 9 MU per dose). The median PFS at second analysis was significantly longer in the sunitinib group compared to IFN- $\alpha$ group (11 vs 5 months, $\mathrm{p}<0.001)$ as a result of which patients in the IFN- $\alpha$ arm were allowed to cross-over to sunitinib arm. ORRs at second analysis were significantly higher in the sunitinib arm compared to IFN- $\alpha$ arm $(31 \%$ vs $6 \%, p<0.001)$.

On the basis of this data, sunitinib was approved for first line therapy in patients with advanced RCC and emerged as frontline standard of care. Final analyses of the study showed that patients in the sunitinib arm had higher ORR $(47 \%$ vs $12 \%, \mathrm{p}<0.001)$ and reported better quality of life compared to patients in IFN- $\alpha$ group (R. J. Motzer et al., 2009). Median overall survival (OS) was improved with sunitinib compared to IFN- $\alpha$ with borderline statistical significance ( 26.4 vs 21.8 months, $\mathrm{p}=0.051)$. An exploratory analysis which censored 25 patients from the IFN- $\alpha$ group who had crossed over to receive sunitinib, resulted in significantly longer OS with sunitinib (26.4 months vs 20.0 months, $\mathrm{p}=0.036$ ). 
Because of concerns of relapse of cancer during the "two weeks off" period of the standard 4/2 regimen, several dosing schedules for sunitinib are being studied. Continuous dosing of sunitinib ( $37.5 \mathrm{mg}$ orally daily) demonstrated antitumor activity with a manageable safety profile in first and second-line mRCC appearing to be an alternative dosing strategy (Escudier, Roigas, et al., 2009), (Barrios et al., 2011). Phase II EFFECT trial compared the two dosing strategies; sunitinib $50 \mathrm{mg}$ taken daily on $4 / 2$ schedule versus $37.5 \mathrm{mg}$ taken daily continuously in treatment naive mRCC (R. Motzer et al., 2011). Majority of the patients were intermediate risk by Memorial Sloan Kettering Cancer Center (MSKCC) criteria (61\%). ORR, median OS and adverse event (AEs) were comparable with similar discontinuation rates in both the arms. A trend towards inferior time to progression (TTP) was observed in the continuous dosing arm (9.9 months in 4/2 schedule versus 7.1 months in continuous dosing arm, $\mathrm{p}=0.09$ ). Median PFS and compliance were better with the discontinuous regimen as patients appreciated break in toxicities (PFS 8.5 vs 7.0 months, $\mathrm{p}=0.07$ ); $4 / 2$ regimen continues to be the recommended dosing in $\mathrm{mRCC}$.

\subsubsection{Pazopanib}

Pazopanib (GW786034) is an oral multikinase inhibitor that inhibits signaling by VEGFRs, PDGFRs, and c-Kit. It was approved by the FDA in 2009 for first-line treatment of patients with advanced RCC.

A randomized phase II discontinuation trial in 225 patients who were either treatment naïve or progressed on prior cytokine or bevacizumab containing regimen showed durability and tolerability of the agent at a dose of $800 \mathrm{mg}$ once daily with an overall response rate of $35 \%$ and median duration of response of 52 weeks (Hutson et al., 2010). A randomized placebo-controlled phase III study showed significant improvement of PFS and tumor response compared with placebo in treatment naïve and cytokine-pretreated patients with advanced or metastatic RCC (Sternberg et al., 2010). Of 435 enrolled patients, 233 (54\%) were treatment naïve and 202 (46\%) were cytokine pretreated. PFS was significantly prolonged with pazopanib compared to placebo in the overall population (9.2 vs 4.2 months, $\mathrm{p}<0.0001)$; on subpopulation analysis, PFS in pazopanib arm compared to placebo in the treatment naïve patients and cytokine-pretreated patients was 11.1 versus 2.8 months $(\mathrm{p}<0.0001)$ and 7.4 versus 4.2 months $(\mathrm{p}<0.001)$ respectively. The median duration of response was longer than one year and objective response rate was $30 \%$ with pazopanib compared with $3 \%$ in placebo arm $(p<0.001)$. The drug was well tolerated with no evidence of clinically important differences in quality of life compared to placebo; the most common adverse events were diarrhea, hypertension, hair depigmentation and gastrointestinal intolerance (Sternberg et al., 2010).

The efficacy of pazopanib in comparison to sunitinib is not known as the overall survival data from the study is not yet available. An ongoing phase III trial comparing pazopanib and sunitinib in first line setting in locally advanced RCC might provide more answers. ${ }^{4}$

\section{2 mTOR Inhibitors}

\subsubsection{Everolimus}

Everolimus (RAD001) is an oral mammalian target of rapamycin (mTOR) inhibitor approved by FDA in 2009 for the treatment of advanced RCC after disease progression on treatment with sunitinib or sorafenib. It acts via direct antitumor effects by arresting cell cycle progression, inhibiting growth factor stimulation and angiogenesis.

In phase II study by Amato et al, patients with $\mathrm{mRCC}$ who received $\leq$ one prior therapy including chemotherapy, immunotherapy, or a molecular targeted agent other than an mTOR inhibitor were included (Amato, Jac, Giessinger, Saxena, \& Willis, 2009). Of 41 enrolled patients, 37 were evaluable for response. Everolimus was given at daily dose of $10 \mathrm{mg}$. Stable disease for $>$ or $=3$ months and $>$ or $=6$ months was observed in $27(73 \%)$ and $21(57 \%)$ patients respectively. Significant antitumor activity was demonstrated (median PFS and OS of 11.2 and 22.1 months) leading to phase III study.

Renal Cell cancer treatment with Oral RAD001 given Daily (RECORD-1), a randomized phase III trial comparing everolimus with placebo in second line setting was conducted in 416 patients with mRCC who progressed after tyrosine kinase and VEGFR inhibitors (R. J. Motzer et al., 2010). Patients were randomized $(2: 1)$ to everolimus $10 \mathrm{mg}$ daily $(\mathrm{n}=277)$ or placebo $(\mathrm{n}=139)$ plus best supportive care. The trial was terminated early when a statistically significant difference in median PFS was seen between the two groups at second interim analysis (4.0 months in everolimus arm versus 1.9 months in placebo arm, $\mathrm{p}<0.0001)$ (R. J. Motzer et al., 2008); cross-over to everolimus arm was allowed. A subgroup analysis proved that PFS was 3.9, 4.0 or 5.9 months after sunitinib, sorafenib or both, respectively. At final analysis, the PFS benefit with everolimus remained, with a median PFS time of 4.9 months versus 1.9 months with placebo (R. J. Motzer et al., 2010). The 
median OS was comparable between the two arms (14.8 months in everolimus versus 14.4 months in placebo, $\mathrm{p}=0.162$ ) but when the survival was corrected for crossover ( $80 \%$ cross-over to everolimus arm), it was 1.9 -fold longer with everolimus compared with placebo. Patients receiving everolimus had higher rates of grade 3 or 4 stomatitis, infections, and non-infectious pneumonitis. The most common events (grade 1 or 2 ) in everolimus arm were stomatitis, rash, fatigue or asthenia, and diarrhea.

The study established the efficacy and tolerability of everolimus in patients with $\mathrm{mRCC}$ after progression on sorafenib and / or sunitinib based on the improvement in survival and modest side effect profile.

\subsubsection{Temsirolimus}

Temsirolimus (CCI-779), a derivative of rapamycin is an inhibitor of mTOR; activation of mTOR has multiple downstream effects including increased hypoxia-inducible factor 1a (HIF 1A) gene expression (Hudson et al., 2002). Phosphatase and tensin homolog (PTEN) is a tumor suppressor gene that regulates cell cycle progression and cell survival. Reduced expression of PTEN has been demonstrated in RCC patients (Shin Lee, Seok Kim, Bok Kim, Cheol Lee, \& Soo Park, 2003). Loss of PTEN has been associated with Akt phosphorylation, a serine/threonine kinase that plays a critical role in cell survival and proliferation. The activation of mTOR pathway and akt transformation can be inhibited by rapamycin derivatives providing a strong rationale for use of mTOR inhibitors in treatment of RCC (Liu et al., 2004).

For patients with intermediate and poor prognosis, the median survival with temsirolimus appeared to be higher in a phase II study compared to IFN- $\alpha$ treated patients in a comparative model leading to phase III study in poor-risk patients (Atkins et al., 2004; R. J. Motzer, Bacik, Murphy, Russo, \& Mazumdar, 2002).

A three arm phase III study was conducted in 626 poor-prognosis patients comparing temsirolimus versus interferon versus combination of both the drugs. Atleast three of the six poor risk features were required for eligibility: time from diagnosis to first treatment less than one year, corrected serum calcium $>10 \mathrm{mg} / \mathrm{dl}$, lactic dehydrogenase $>1.5$ times the upper limit of normal, Karnofsky performance score of 60 or 70 , hemoglobin less than lower limit of normal and multiple organ sites of metastases (Hudes et al., 2007). Two-thirds of participants had undergone prior nephrectomy, and $>80 \%$ had predominantly clear-cell histology. Patients were randomly assigned to receive $25 \mathrm{mg}$ of intravenous temsirolimus weekly, 3 million units of interferon alfa (with an increase to 18 million $\mathrm{U}$ ) subcutaneously three times weekly, or combination therapy with $15 \mathrm{mg}$ of temsirolimus weekly plus 6 million $\mathrm{U}$ of interferon alfa three times weekly. The combination group had higher grade 3 or 4 adverse events compared to temsirolimus alone arm ( 67 vs $87 \%, p=0.02$ ) consequently leading to more treatment delays and dose reductions. The mean dose intensity of temsirolimus was also lower in the combination-therapy group than in the temsirolimus group (10.9 mg vs. $23.1 \mathrm{mg}$ per week; $92 \mathrm{vs} 73 \%$ of planned weekly dose). OS was significantly longer in the temsirolimus arm (10.9 months) as compared to the combination arm ( 8.4 months) and to IFN alone ( 7.3 months) though the dose reductions and adverse events could partly have affected the overall survival in the combination-therapy group.

Consequently, temsirolimus got approved for advanced RCC in 2007 and is now considered a standard first-line therapy for patients with poor-risk features.

\subsection{Anti VEGF Monoclonal Antibody}

\subsubsection{Bevacizumab and IFN- $\alpha$}

A phase II trial of bevacizumab, a humanized monoclonal antibody compared placebo to bevacizumab at doses of 3 and $10 \mathrm{mg}$ per kilogram of body weight given every two weeks in patients with cytokine refractory disease (Yang, Haworth, et al., 2003). While PFS in the high-dose bevacizumab was significantly longer than placebo group (4.8 vs 2.5 months, $\mathrm{p}<0.001$ ), the difference between time to progression (TTP) in the low-dose bevacizumab and placebo groups was of borderline statistical significance $(\mathrm{p}=0.041)$ suggesting efficacy of high dose bevacizumab in patients with metastatic renal cell cancer. There was however, no significant differences in overall survival between groups ( $\mathrm{p}>0.20)$.

Two phase III randomized multi-center trials, AVOREN and CALGB 90206 established the role of bevacizumab in combination with interferon in the front-line setting. Both the studies compared bevacizumab plus interferon- $\alpha$ to interferon- $\alpha$ alone in previously untreated mRCC (Escudier et al., 2010), (B. I. Rini et al., 2010). The studies evaluated the same doses of bevacizumab $(10 \mathrm{mg} / \mathrm{kg}$ every two weeks) and IFN- $\alpha$ (9 million units thrice weekly). In the AVOREN (Avastin and Roferon in Renal Cell Carcinoma, $n=649$ ) study, the addition of bevacizumab to interferon significantly increased the PFS (10.2 vs 5.4 months, $\mathrm{p}=0.0001)$ (Escudier et al., 2010). Similar benefit was demonstrated in CALGB 90206 (Cancer and Leukemia Group B, 8.5 vs 5.2 months, $\mathrm{p}<0.0001)$ (B. I. Rini et al., 2010). In both the trials, there was a trend towards longer survival in the combination 
arm but the difference was not statistically significant, the reason of which is unclear and could be a result of one or more confounding factors. In the AVOREN trial, cross-over was allowed to bevacizumab arm after favorable PFS was observed in interim analysis; censoring those patients could have impacted the final OS. The other confounding factor could be the use of subsequent TKIs in both the trials and subsequent improvement in survival. More than half of the patients in AVOREN study received poststudy therapies ( $>35 \%$ received TKIs, sorafenib and sunitinib). In the CALGB 90206 trial, though cross-over was not allowed, most of the patients received subsequent therapies.

AVOREN and CALGB 90206 clearly demonstrated improved response rates and progression free survival in treatment-naïve patients with advanced RCC. The dose of IFN- $\alpha$ can be reduced to decrease interferon related adverse effects without compromising the efficacy suggesting bevacizumab as a good option as first-line therapy in setting of metastatic RCC (Melichar et al., 2008). The study also demonstrated that treatment with TKIs following bevacizumab is an efficacious option.

\section{Sequential Therapy in Renal Cell Carcinoma: Optimizing therapy with molecular targeted agents}

Despite significant improvements in the systemic treatment of mRCC, the optimal sequence of targeted therapy remains a matter of debate. In patients without significant comorbidities and good-risk RCC, immunotherapy with high dose IL-2 continues to play a role due to complete and durable responses in up to $10 \%$ of the patients (Yang, Sherry, et al., 2003),(McDermott et al., 2005). In patients ineligible for high dose IL-2, first line therapy includes multikinase inhibitor, sunitinib or pazopanib or anti-VEGF monoclonal antibody, bevacizumab in combination with interferon- $\alpha$. In patients with poor-risk mRCC, temsirolimus showed improvement in OS and PFS compared to IFN- $\alpha$; hence recommended as first line therapy in poor-risk patients (Hudes et al., 2007). Eventually all patients on first-line therapy have disease progression or prohibitive toxicities requiring switch to second-line targeted therapy (Table 2).

Table 2. Sequential therapy-treatments algorithm

\begin{tabular}{lll}
\hline $\begin{array}{l}\text { Clear cell renal } \\
\text { carcinoma }\end{array}$ & First line therapy & Second line therapy \\
\hline $\begin{array}{l}\text { Good and } \\
\text { Intermediate risk }\end{array}$ & $\begin{array}{l}\text { Immunotherapy for patients with } \\
\text { good performance status. }\end{array}$ & $\begin{array}{l}\text { Prior IL-2: Sorafenib or Pazopanib or Sunitinib } \\
\text { Prior VEGFR-TKI: Good risk: Everolimus } \\
\end{array}$ \\
& $\begin{array}{l}\text { Sunitinib (or) Bevacizumab + IFN- } \alpha \\
\text { (or) Pazopanib (or) Sorafenib for } \\
\text { patients not eligible for cytokine } \\
\text { therapy }\end{array}$ & $\begin{array}{l}\text { Prior Bevacizumab: Sunitinib } \\
\text { Clinical trials are a good option as second line for } \\
\text { all prior therapies. }\end{array}$ \\
& Temsirolimus & Clinical trial \\
Poor risk & & Sunitinib or sorafenib (Insufficient evidence) \\
& &
\end{tabular}

\subsection{Second Line Therapy Following Prior Immunotherapy / Cytokines}

\subsubsection{Sunitinib}

Sunitinib was initially approved for second line therapy based on ORR of up to $40 \%$ and PFS of 8.2 months in all patients and better PFS in those with complete and partial responses (14.8 months) (R. J. Motzer, Michaelson, et al., 2006; R. J. Motzer, Rini, et al., 2006).

\subsubsection{Sorafenib}

A randomized phase II trial comparing sorafenib (400 mg twice daily) to interferon $\alpha$-2a in treatment naïve patients with mRCC showed similar PFS in the two arms prior to dose escalation (600 mg twice daily) and cross-over (Escudier, Szczylik, et al., 2009). 76\% of patients who were switched from IFN-2 $\alpha$ to sorafenib after disease progression had tumor reductions suggesting clinical utility of sorafenib after IFN- $\alpha-2 a$ failure (median PFS of 5.3 months who crossed-over). Survival advantage was seen with sorafenib over placebo in cytokine refractory patients with good and intermediate risk $\mathrm{mRCC}$ in TARGET study leading to its approval (Escudier et al., 2007). 


\subsubsection{Pazopanib}

Pazopanib showed an ORR of $35 \%$ and an excellent median duration of response of 52 weeks in a phase II discontinuation trial in patients who were either treatment-naïve or progressed on prior cytokine or bevacizumab containing regimen (Hutson et al., 2010). Similar results were reproduced in pivotal phase III trial; median duration of response was longer than one year and ORR was 30\% (Sternberg et al., 2010). PFS was significantly prolonged with pazopanib compared to placebo in the overall population $(9.2$ vs 4.2 months, $p<0.0001)$; on subpopulation analysis, PFS in pazopanib arm compared to placebo in the treatment naïve patients and cytokine-pretreated patients was 11.1 versus 2.8 months $(p<0.0001)$ and 7.4 versus 4.2 months $(p<0.001)$ respectively. Bevacizumab and temsirolimus showed moderate benefit in phase II clinical trials (Yang, Sherry, et al., 2003; Atkins et al., 2004). The use of sorafenib and pazopanib is supported by level 1 evidence.

\subsection{Second Line Therapy Following Prior Multikinase Inhibitor}

\subsection{1 mTOR inhibitor}

mTOR inhibitors block VEGF-driven angiogenesis by mechanisms that are different from those for VEGF/VEGFR inhibitors. While sorafenib and sunitinib reduce the kinase activity of the VEGF and PDGF receptors, mTOR inhibitors block the synthesis of VEGF by tumor cells and signaling downstream of the receptors that might explain its role in patients who no longer respond to the VEGFR inhibitors (Amato et al., 2009).

\subsubsection{A. Everolimus}

Phase III randomized study, RECORD-1 comparing everolimus with placebo was conducted in 416 patients with mRCC who progressed after tyrosine kinase and VEGFR inhibitors (R. J. Motzer et al., 2010). Among patients enrolled, $21 \%$ had received one prior TKI, $53 \%$ had received one TKI and at least one other agent (commonly a cytokine or bevacizumab), and $26 \%$ had received both TKIs with or without additional therapy. Patients were randomized $(2: 1)$ to everolimus $10 \mathrm{mg}$ daily $(\mathrm{n}=277)$ or placebo $(\mathrm{n}=139)$ plus best supportive care. The trial was terminated early when a statistically significant difference in median PFS was seen between the two groups at second interim analysis (4.0 months in everolimus arm versus 1.9 months in placebo arm, p<0.0001) (R. J. Motzer et al., 2008); cross-over to everolimus arm was allowed. A subgroup analysis proved that PFS was 3.9, 4.0 or 5.9 months after sunitinib, sorafenib or both, respectively. At final analysis, the PFS benefit with everolimus remained, with a median PFS time of 4.9 months versus 1.9 months with placebo (R. J. Motzer et al., 2010). The median OS was comparable between the two arms (14.8 months in everolimus versus 14.4 months in placebo, $\mathrm{p}=0.162$ ) but when the survival was corrected for crossover ( $80 \%$ cross-over to everolimus arm), it was 1.9-fold longer with everolimus compared with placebo. Patients in the everolimus group who received prior sunitinib had a smaller PFS benefit when compared with those who received prior sorafenib (3.9 versus 5.9 months).

\subsubsection{B. Temsirolimus}

A retrospective analysis examined efficacy of temsirolimus in 87 patients who received atleast one prior VEGF-directed therapy. Prior therapy included sunitinib (85\%), sorafenib (51\%), IFN (21\%), bevacizumab (7\%) and chemotherapy (Mackenzie et al., 2011). The majority of patients had either intermediate or poor-prognosis disease at baseline. Of the 77 assessable patients, no complete responses were seen. Partial responses were observed in 5\% of patients, and stable disease was observed in $65 \%$. The median OS was 11.2 months and median TTP was 3.9 months (2.6 months in the poor-prognosis group and 4.8 months in the intermediate-risk group). There was no significant difference in the TTP between patients who had received more than one VEGF inhibitor before temsirolimus and those who received only one VEGF inhibitor (3.73 versus 3.97 months) suggesting degree of prior treatment did not have an impact.

The efficacy was comparable to everolimus trial despite the fact that patients in the temsirolimus trial were heavily treated, and included patients with a worse functional status. While patients with ECOG 3 were included in temsirolimus study, everolimus trial excluded patients with Karnofsky performance status worse than $70 \%$. There was higher number of patients in poor-prognosis group in temsirolimus trial compared to everolimus study ( $36 \%$ vs $15 \%$ ) suggesting temsirolimus may be the preferable modality as second line agent in poor-risk patients as in the front-line setting. 


\subsection{VEGF Targeting Multikinase Inhibitor-TKI}

\subsubsection{Sorafenib-Sunitinib or Sunitinib-Sorafenib}

Despite lack of randomized trials, sequential therapy with sorafenib and sunitinib is a commonly used therapeutic strategy. Many retrospective studies demonstrated superiority of sequence of sorafenib followed by sunitinib compared to sunitinib followed by sorafenib with significantly better OS and longer PFS suggesting lack of cross-resistance among the TKIs (Sablin et al., 2009; Dudek, Zolnierek, Dham, Lindgren, \& Szczylik, 2009; Porta et al., 2011). It is proposed that the higher responses with sorafenib-sunitinib sequence are due to greater affinity and wider spectrum of inhibition of tyrosine kinases by sunitinib in comparison to sorafenib (Karaman et al., 2008). Prospective studies on optimal sequencing are ongoing. Pazopanib demonstrated modest activity in patients who received prior sunitinib or bevacizumab in a phase II trial with a median PFS of 9.2 months and ORR of $20 \%$ (Reeves et al., 2011).

\subsubsection{Axitinib}

A recent phase III trial compared axitinib, a potent and selective second generation inhibitor of VEGF receptor to sorafenib as second line therapy in patients who progressed on sunitinib, bevacizumab plus interferon-alfa, temsirolimus and cytokines (B. I. Rini, B. Escudier, et al., 2011). A total of 723 patients were randomly assigned (1:1) to either axitinib ( $\mathrm{n}-361 ; 5 \mathrm{mg}$ twice daily) or sorafenib ( $\mathrm{n}=362 ; 400 \mathrm{mg}$ twice daily). Axitinib dose increases to $7 \mathrm{mg}$ and then to $10 \mathrm{mg}$, twice daily, were allowed for those patients without hypertension or adverse reactions above grade 2. The median PFS was higher in axitinib group (6.7 months) compared to 4.7 months with sorafenib (hazard ratio 0.665 ; one-sided $\mathrm{p}<0.0001$ ). The ORR with axitinib was also superior, at $19.4 \%$, compared with an ORR of $9.4 \%$ with sorafenib. On subgroup analysis, in patients who had previously received cytokines, median PFS was 12.1 months for axitinib and 6.5 months for sorafenib $(p<0 \cdot 0001)$. In patients previously treated with sunitinib, median PFS was 4.8 months for axitinib and 3.4 months for sorafenib $(p=0.0107)$. Treatment was discontinued because of toxicity in $14(4 \%)$ of 359 patients treated with axitinib and $29(8 \%)$ of 355 patients treated with sorafenib. The most common adverse events were diarrhea, hypertension, and fatigue in the axitinib arm, and diarrhea, palmar-plantar erythrodysesthesia, and alopecia in the sorafenib arm. The benefit of axitinib was preserved across various prognostic groups along with good tolerability making it a good option as second-line therapy. Axitinib is currently under FDA review for approval.

\subsubsection{Everolimus}

A recent retrospective study compared sequential everolimus (EV) versus TKI following failure of first tyrosine kinase inhibitor (sorafenib or sunitinib) (Busch et al., 2011). The response rates were not significantly different between the two groups (51.6\% in EV versus $43.5 \%$ in TKI groups). There was however a trend towards improved overall survival for everolimus group ( 43 months for EV and 29 months for TKI; $p=0.03$ ) though the statistical significance was lost in multi-variable adjusted analyses.

Everolimus remains the preferred option in patients who progressed after initial tyrosine kinase inhibitors based on the available evidence.

\subsection{Second Line Therapy Following Bevacizumab}

\subsubsection{Sunitinib}

Sunitinib has substantial antitumor activity in patients with bevacizumab-refractory mRCC. Sixty-one patients who had disease progression on bevacizumab-based therapy received oral sunitinib $50 \mathrm{mg}$ once daily in 6-week cycles on a $4 / 2$ schedule in a phase II study (B. I. Rini et al., 2008). An overall response rate of $23.0 \%$ was observed. Median PFS and OS were 30 and 47 weeks respectively. Following sunitinib therapy, 14 patients (23\%) experienced PRs lasting 44.1 weeks (median), 36 (59\%) had stable disease, five (8\%) had progressive disease, and six patients were not considered evaluable. The treatment was well tolerated and most common side effects included fatigue (34\%), hypertension (18\%) and hand-foot syndrome (10\%). The study supported the hypotheses that sunitinib may act at signaling pathways involved in bevacizumab resistance.

\subsubsection{Sorafenib}

In another prospective phase II study, modest clinical activity was seen with sorafenib. 48 patients who progressed after either sunitinib or bevacizumab were treated with $400 \mathrm{mg}$ twice daily of sorafenib (J. A. Garcia et al., 2010). Tumor burden reduction rate of $30 \%$ was observed ( $>5 \%$ tumor reduction was seen in 14 of 48 patients). Among the 14 patients, 8 patients had received prior sunitinib, and 6 patients had received prior bevacizumab. The estimated median PFS for the entire cohort was 4.4 months and was not impacted by the type of prior anti-VEGF therapy. 


\subsection{Second Line Therapy Following Mtor Inhibitors}

There is lack of high-level evidence to guide therapy after mTOR inhibitors and additional prospective randomized studies are needed in this setting. Therapy with mTOR inhibitors can lead to resistance via compensatory hypoxia inducible factor (HIF) activation which could be addressed by VEGF targeting agents such as sunitinib, sorafenib and bevacizumab (B. I. Rini, 2010).

\subsubsection{Sorafenib}

Third line sorafenib appeared to be active and well tolerated in advanced RCC patients after first-line sunitinib and second-line everolimus and temsirolimus (Di Lorenzo et al., 2010). 34 patients were eligible out of total of 150 patients treated with first-line sunitinib. Median PFS and OS of 4 and 7 months respectively were observed. Eight patients showed partial response with an overall disease control rate of $44 \%$. The response to third-line sorafenib was however associated with response to first-line sunitinib. Response rate (RR) to sorafenib was $47 \%$ in patients who responded to sunitinib, where as $0 \%$ in patients who had not responded $(\mathrm{p}=0.0027)$ suggesting that response to prior treatment with sunitinib might play an important role in initiating sorafenib as third-line agent after mTOR inhibitors.

\subsubsection{Sunitinib-Rechallenge}

Another study analyzed the efficacy of sunitinib-rechallenge in thirteen patients after progression on mTOR inhibitors (Grunwald et al., 2011). Initial treatment with sunitinib was associated with median PFS of 21 months with 2 patients achieving complete remission (CR) and seven with partial response (54\%). After re-exposure to sunitinib, 12 of 13 patients showed clinical benefit. 10 patients (77\%) had disease stabilization and median PFS of 6.9 months was observed. The study also underscored the consideration of TKI re-challenge in mRCC.

\subsection{Immunotherapy Following VEGF Targeted Therapy}

The safety and efficacy of high dose IL-2 after prior therapy with VEGF-targeted agents remains unexplored. In a retrospective study of 23 patients who received salvage IL-2 after targeted therapy, fifteen patients received bevacizumab either as their only targeted therapy or as sequential therapy and $15(65 \%)$ of the 23 patients received prior TKI (sorafenib or sunitinib). Only one of 23 patients proceeded to second cycle of IL-2. No patients achieved PR or CR; 19 patients progressed, 3 patients had stable disease and one patient died during the treatment. The patients who received prior TKI were less tolerant to the treatment compared with patients who received prior bevacizumab. Six of 23 patients $(26 \%)$ experienced severe cardiovascular toxicity (all received prior TKI). This study though small and retrospective in nature points towards increased toxicity, especially cardiovascular with IL-2 after prior TKIs in addition to inadequate efficacy.

Sequential and combination therapy in advanced renal cell carcinoma is an evolving field. A better understanding of the mechanism of tumor progression and treatment resistance may help in defining an optimal strategy for sequencing the molecular targeted agents. Clinical decision making is influenced by previous therapy, patient comorbidities, toxicity profile and patient preferences.

\section{Common Toxicities of Targeted Therapy and Management Strategies}

Tyrosine kinase inhibitors, sunitinib and sorafenib are commonly associated with hypertension, fatigue, hand-foot syndrome, diarrhea, myelosuppression, elevated lipase and thyroid dysfunction (Table 1). Secondary erythrocytosis has been well described as an adverse effect, the etiology of which is unknown (Alexandrescu, McClure, Farzanmehr, \& Dasanu, 2008). VEGF is a negative regulator of hepatic erythropoietin (EPO) synthesis and its blockade could upregulate the EPO leading to erythrocytosis (Tam et al., 2006). Thyroid function should be assessed on a regular basis while on TKIs. Cardiac monitoring is essential in patients on sunitinib due to complications of hypertension and congestive heart failure, especially if diagnosed with coronary artery disease or other cardiac risk factors.

Bevacizumab has similar side effect profile as in other malignancies. The adverse effects are related to inhibition of VEGF mediated signaling with hypertension and proteinuria being the commonly observed side effects. Other rare complications include bleeding, thromboembolism and impaired wound healing. IFN, when used in combination with bevacizumab, is associated with both acute and chronic symptoms such as fatigue, influenza-like illness, myelosuppression, and depression.

mTOR inhibitors have a side effect profile distinct from VEGF and multikinase inhibitors. They cause dyslipidemia and hyperglycemia. Another complication associated with mTOR inhibitors is interstitial lung disease or pneumonitis. Other common side effects include fatigue, diarrhea, nausea, rash and stomatitis. 
Treatment related toxicities and their management

\subsection{Constitutional Symptoms}

Constitutional symptoms associated with targeted therapy include fatigue, influenza-like illness, infections, weight loss and depression. Besides underlying malignancy and disease progression, fatigue could be related to intolerance to medication, depression, anxiety, anemia, thyroid dysfunction, deconditioning and other comorbidities and has to be thoroughly investigated. If no etiology is defined, nonpharmacologic interventions such as counseling or psychosocial intervention, regular exercise or physical activity and rehabilitation could be advised. Incase of persistent grade 3 or 4 fatigue, dose reduction or treatment interruption may be needed.

\subsection{Cardiac Toxicity}

Incidence of grade 3 or 4 hypertension in metaanalyses of trials conducted with VEGF inhibitor and TKIs was less than $10 \%$ in patients with $\mathrm{mRCC}(6.5 \%$ with sorafenib, $7.1 \%$ with bevacizumab and $8.3 \%$ with sunitinib) (Di Lorenzo et al., 2011). Antihypertensives are tailored to patient's characteristics, with consideration given to comorbidities, contraindications and other interactions. Patients with diabetes mellitus could benefit from addition of angiotensin-converting enzyme inhibitors (ACEI) or angiotensin II receptor blockers (ARB) and those with coronary artery disease can derive advantage from beta blockers. In case of life threatening event, the therapy should be suspended and could be restarted at a lower dose after careful reevaluation. In the context of a second life threatening event, the therapy should be discontinued indefinitely.

VEGF directed agents interfere with regenerative capacity of endothelial cells and cause defects that expose pro-coagulant phospholipids on the luminal plasma membrane leading to thrombosis or hemorrhage. Treatment with bevacizumab is associated with increased risk of stroke, transient ischemic attacks, myocardial infarction and angina. Treatment with sunitinib and sorafenib is also associated with increased risk of thromboembolic events but to a lesser degree (Skillings et al., 2005). Patients should be carefully monitored with careful physical examination and medical history. For grades 2 to 4 thrombotic and bleeding events, the treatment is held until recovery to grade 1 along with appropriate medical management.

Patients treated with sunitinib and sorafenib must be carefully monitored for left ventricular cardiac dysfunction (LVCD) that is likely caused by direct myocyte toxicity in addition to hypertension. The overall incidence of LVCD in patients receiving sunitinib in a phase III trial by Motzger and colleagues was $10 \%$ (grade 3 of $2 \%$ ) (R. J. Motzer et al., 2007).

Echocardiographic and clinical assessments should be performed prior to initiation of treatment and at regular intervals, especially in patients with cardiovascular risk factors. Prior initiation of ACEI and beta-blockers to ensure normal blood pressures and to prevent TKI mediated cardiotoxicity is reasonable. Statin medications which are cardioprotective via activation of nitric oxide synthase may be considered.

\subsection{Respiratory Toxicity}

Drug related noninfectious pneumonitis is a class-effect toxicity of mTOR inhibitors. In patients taking everolimus, an incidence of $14 \%$ (37/274 patients; $4 \%$ with grade 3 ) was recorded in a phase III trial by Motzger et al. (R. J. Motzer et al., 2010). There were similar lung toxicities with temsirolimus. Retrospective radiographic review of patients in a phase III study showed that 52 of 178 patients $(29 \%)$ had radiographically identified drug-related pneumonitis (Maroto et al., 2011). Increased cough and dyspnea were the most common respiratory symptoms and can present radiographically as ground glass attenuation and / or patchy consolidation; Non-invasive management of pneumonitis by the Memorial Sloan Kettering group showed favorable outcome (White et al., 2010). Early and prompt intervention is important in management of noninfectious pneumonitis.

\subsection{Endocrinologic Toxicity}

TKIs are associated with thyroid function abnormalities. Several mechanisms of sunitinib induced hypothyroidism have been suggested including destructive thyroiditis, reduced synthesis of thyroid hormones related to inhibition of thyroid peroxidase activity and drug-induced regression of the gland vascular bed with significant capillary alteration (Desai et al., 2006; Wong et al., 2007; B. I. Rini et al., 2007). Thyroid function (serum TSH, free $\mathrm{T}_{4}$, thyroid antibodies) should be assessed at baseline and during the treatment. The American Thyroid Association recommends against routine treatment in asymptomatic hypothyroid patients (serum TSH 4.5-10.0 mIU/L) (Surks et al., 2004). Patients who have overt hypothyroidism with increased thyroid peroxidase or thyroglobulin antibody titers or symptoms should be treated with thyroid replacement to achieve target TSH level of (0.5-2.5 mU/L). If the symptoms do not improve despite hormone replacement, dose reduction and withdrawal of TKI is considered only after other possible causes of the symptomatology are excluded and euthyroid status has been reached and maintained (Torino, Corsello, Longo, Barnabei, \& Gasparini, 2009). 


\subsection{Metabolic Toxicity}

Metabolic disturbances including hyperglycemia, hypertriglyceridemia and hypercholesterolemia are commonly observed with mTOR inhibitors and pazopanib. The incidence of grade 1/ 2 hyperglycemia in patients treated with pazopanib was $41 \%$ (Sternberg et al., 2010).

In phase III trials, $15 \%$ and $11 \%$ of patients treated with everolimus and temsirolimus, respectively had grade 3-4 hyperglycemia (Di Lorenzo et al., 2011). While sulfonylureas and biguanides are contraindicated in renal dysfunction, glitazones and biguanides are avoided in patients with impaired liver function. Pharmacologic treatment could start with insulin sensitizer such as metformin along with dietary and life style modifications. If glycemic control goals are not reached, sulfonylureas or glitazones could be added and consultation with endocrinologist should be considered.

More than $70 \%$ of patients treated with everolimus developed hyperlipidemia in trials (Di Lorenzo et al., 2011). Concomitant cardiovascular risk factors should be assessed and treatment with lipid lowering agents should be initiated to reach target cholesterol levels along with dietary and life style modifications. Statins are drugs of first choice and bile acid sequestrants such as nicotinic acid and cholestryamine can be added to reach target LDL (low density cholesterol) level.

\subsection{GI toxicity}

Nausea, vomiting, anorexia and diarrhea are frequently noted adverse events with targeted therapy and rarely required treatment discontinuation in the trials. Bevacizumab is associated with rare but life threatening complication of gastrointestinal perforation. In a meta-analysis of randomized controlled trials (RCT), higher risk was observed in patients with renal cell cancer (risk ratio 5.67; confidence interval 0.66-48.2) and colorectal carcinoma (Hapani, Chu, \& Wu, 2009). The overall incidence of gastrointestinal perforation was $0.9 \%$ among patients receiving bevacizumab, with a mortality of $21.7 \%(11.5-37.0)$. Treatment discontinuation is warranted if this complication is encountered.

Hepatic toxicity is frequently observed with sunitinib and pazopanib $(\sim 50 \%$ of patients had elevated transaminases in phase III trials) (Di Lorenzo et al., 2011). The treatment should be interrupted for grade $3 / 4$ toxicity and discontinued if there is no resolution.

\subsection{Skin Toxicity}

Skin rash and hand-foot skin reaction (HFSR) are commonly encountered toxicities with multikinase inhibitors, sorafenib and sunitinib. HFSR encompasses symptoms of dysesthesia and paresthesia (which may be the first symptoms to appear), erythema, edema, hyperkeratosis, dry skin, callous-like blisters and desquamation (Robert, Mateus, Spatz, Wechsler, \& Escudier, 2009). Treatment is mainly supportive for grade 1 with topical intervention (urea based keratolytic agents). If there is no improvement in grade 2 HFSR (skin changes present but no interference with function) despite supportive and topical measures, dose reduction by one level should be considered. If there is no resolution of the toxicity to grade 0 or 1 despite dose reduction, the treatment should be withheld till resolution to grade 0 or 1 and restarted at the lower dose). In the event that HFSR reaches grade 3 (skin changes along with pain interfering with function), treatment interruption for a minimum of 7 days, combined with symptomatic treatment, is recommended until symptoms return to grade 0 or 1 . When treatment is resumed, the dose should be decreased by one dose level ( $400 \mathrm{mg}$ daily). If symptoms remain at grade 0 or 1 for a minimum of 7 days, the treatment can be increased by one dose level. On the third occurrence of grade 3 symptoms, it is recommended that the treatment be discontinued (Robert et al., 2009).

Most side effects from the use of these targeted agents can be managed with medical management or supportive measures. Some of the adverse events however can affect the quality of life and often need dose reduction and occasionally discontinuation of the treatment. Based on the adverse effect profile, the preference of one targeted agent over another can be justified at times.

\section{Biomarkers Predicting Response to Targeted Therapy}

The identification of biomarkers that predict response to targeted therapy will aid in patient selection and guide therapy because of increasing choices in treatment. With diverse toxicity profile of the molecular targeted agents, predictors of serious adverse events could help in tailoring therapy and personalize medicine.

\subsection{Motzer Criteria}

Initial risk stratification was established by Motzer et al known as MSKCC system or informally as the "Motzer criteria" (R. J. Motzer et al., 1999). The relationship between pretreatment clinical features and survival was studied in 670 patients with advanced RCC. Five prognostic factors for predicting survival were identified and 
used to categorize patients into favorable, intermediate and poor risk categories. Shorter survival was associated with low Karnofsky performance status; $(<80 \%)$, high "corrected" serum calcium $(10 \mathrm{mg} / \mathrm{dl})$, high serum lactate dehydrogenase ( $>1.5$ times upper limit of normal), low hemoglobin (less than lower limit of normal) and absence of prior nephrectomy. Patients with none of these risk factors survived the longest and were considered a favorable-risk group (20 months). Patients with one or two risk factors constituted an intermediate-risk group (10 months), whereas those with three or more risk factors had the poorest survival and represented a poor-risk group (4 months). This risk classification was further validated in subsequent analyses and now widely used as standard criteria for recommending treatment options in addition to selecting patients for participation in clinical trials as well as comparing outcomes of drugs. The same group from MSKCC identified prognostic factors for PFS and OS with sunitinib as first-line metastatic RCC therapy (Patil et al., 2011). Multivariate analysis of PFS identified five independent predictors, including serum lactate dehydrogenase (LDH) level, presence of $\geq 2$ metastatic sites, no prior nephrectomy, Eastern Cooperative Oncology Group (ECOG) performance status, and baseline platelet count, while multivariate analysis of OS identified serum LDH level, corrected serum calcium level, time from diagnosis to treatment, hemoglobin level, ECOG performance status, and presence of bone metastasis as predictors suggesting that the MSKCC model is applicable in the era of targeted therapy.

\subsection{Clinical Markers}

Hypertension (HTN) is associated with statistically significant improved clinical outcome in patients treated with targeted agents such as bevacizumab and sunitinib (B. I. Rini, D. P. Cohen, et al., 2011; Bono et al., 2009; Scartozzi et al., 2009). In a retrospective exploratory analysis in more than 500 patients, median PFS and OS were more than fourfold longer for patients with HTN defined as systolic blood pressure of at least $140 \mathrm{~mm} \mathrm{Hg}$ compared with patients without HTN (B. I. Rini, D. P. Cohen, et al., 2011). ORR was more than six times greater and a statistically significant decrease in the relative risk of disease progression and death was seen in patients who developed hypertension suggesting hypertension as a good biomarker of antitumor efficacy.

Erythrocyte sedimentation rate (ESR) kinetics has been proposed as another potential prognostic marker (Zhang et al., 2011). Brain natriuretic peptide precursor (NT-pro-BNP) was reported as potential surrogate marker in a small cohort of patients treated with sunitinib $(\mathrm{N}=36)$ (Papazisis et al., 2010). Patients with disease progression had significantly higher plasma BNP levels compared with those who had clinical benefit evident as early as 15 days of initiation of treatment. Median PFS was 3.9 months in patients $(n=13)$ with more than 1.5 fold increases in plasma NT-pro-BNP after 15 days of treatment and 12.0 months in patients $(n=22)$ where plasma NT-pro-BNP showed less than 1.5 fold increases or baseline or lower values $(\mathrm{p}=0.001)$. This needs to be further addressed in a larger cohort of patients.

\subsection{Molecular Markers}

Several molecular and genetic tissue markers have been investigated as potential prognostic factors for renal cell carcinoma. VEGF expression is associated with more aggressive tumor phenotype (Jacobsen et al., 2004). Tumors invading the renal capsule had higher VEGF expression compared to those confined to the kidney $(\mathrm{p}=0.0003)$. Other markers involved in renal tumor biology are carbonic anhydrase IX (CAIX) and tissue inhibitors of metalloproteinases (TIMP). CAIX regulates intracellular $\mathrm{pH}$ in response to hypoxia and is highly expressed in advanced RCC and not in normal kidney (Chiche et al., 2009). High CAIX has been associated with improved prognosis in advanced RCC (Bui et al., 2003). The family of matrix-metalloproteinases and their inhibitors play a crucial role in matrix degradation by tumor cells. Elevated TIMP-1 levels are associated with poor survival prognosis in many tumor types including RCC (Pena, Lathia, Shan, Escudier, \& Bukowski, 2010).

At present, there is no validated biomarker based on which a specific targeted therapy is chosen or optimal sequential therapy is determined. Future efforts should be directed towards integrating the clinical and molecular prognostic markers into nomograms for improving our ability to predict prognosis of renal cell carcinoma.

\section{Future and Ongoing Trials}

There is an ongoing quest for developing more effective and less toxic targeted agents for metastatic renal cell carcinoma. Axitinib and Tivozanib show promising data based on phase II and III studies. There are several other novel targeted therapies that are currently under active investigation (Table 3 ). 
Table 3. Agents in investigation in advanced renal cell carcinoma

\begin{tabular}{|c|c|c|}
\hline Agent & Target & Trials \\
\hline AV-951 & VEGFR & $\begin{array}{l}\text { Phase III TIVO-1 comparing AV-951 to sorafenib } \\
\text { (Tivozanib) in patients with advanced RCC }\end{array}$ \\
\hline AZD2171 & VEGFR c-kit, PDGFR $\beta$ & Phase II -single agent in refractory metastatic RCC \\
\hline IMC-1121B & VEGFR & Phase II in patients treated with prior TKI \\
\hline AVE0005 & VEGF Trap & Phase II ongoing testing two different dosing regimens \\
\hline AMG836 & Angiopoietin & $\begin{array}{l}\text { Phase II study in combination with sunitinib in first } \\
\text { line or after cytokine failure }\end{array}$ \\
\hline Perifosine & $\mathrm{AKT} / \mathrm{PI} 3 \mathrm{~K}$ & $\begin{array}{l}\text { Two Phase II studies in patients who progressed on } \\
\text { TKI and VEGF receptor inhibitor completed and } \\
\text { results awaited }\end{array}$ \\
\hline Ispinesib & kinesin spindle & $\begin{array}{l}\text { Phase II-single agent in metastatic or unresectable } \\
\text { RCC Protein inhibitor }\end{array}$ \\
\hline $\begin{array}{l}\text { Panobinostat } \\
\text { Vorinostat }\end{array}$ & HDAC & $\begin{array}{l}\text { Single agent and combination therapies in patients } \\
\text { progressing on TKI or in first line setting }\end{array}$ \\
\hline \multicolumn{3}{|c|}{ Immunotherapeutic approaches } \\
\hline $\begin{array}{l}\text { MDX-1105/1106 } \\
\text { (monoclonal } \\
\text { Antibody) }\end{array}$ & $\begin{array}{l}\text { Programmed death } \\
\text { ligand }\end{array}$ & Phase II -single agent studies \\
\hline Ipilimumab & CTLA-4 & Phase II trial completed \\
\hline AP12009 & TGF-beta & Phase I ongoing \\
\hline AGS-003 & $\begin{array}{l}\text { Dendritic-cell protein } \\
\text { fusions }\end{array}$ & $\begin{array}{l}\text { Phase II trials as single agent and in combination with } \\
\text { sunitinib in previously untreated renal cell carcinoma }\end{array}$ \\
\hline \multicolumn{3}{|c|}{$\begin{array}{l}\text { VEGFR: vascular endothelial growth factor receptor; PDGFR: platelet derived growth factor receptor; TKI: } \\
\text { tyrosine kinase inhibitor; RCC: renal cell carcinoma; PI3K: phosphoinositide } 3 \text { kinase; HDAC: histone } \\
\text { deacetylase; }\end{array}$} \\
\hline \multicolumn{3}{|c|}{ CTLA4: Cytotoxic T-lymphocyte Antigen 4} \\
\hline
\end{tabular}

\subsection{Axitinib (AG-013736)}

Axitinib is a potent and selective second-generation inhibitor of VEGFR 1, 2 and 3. In a phase II study of patients with cytokine-refractory renal cell carcinoma, an objective response rate of $44 \%$ was observed, with a median time to progression and OS of 15.7 and 29.9 months respectively (Rixe et al., 2007). AXIS trial compared axitinib to sorafenib as second-line therapy in patients who progressed on sunitinib, bevacizumab plus interferon-alfa, temsirolimus and cytokines (Rini, Escudier, et al., 2011). Axitinib group showed a significantly longer PFS (6.7 months) compared to 4.7 months in sorafenib group (hazard ratio 0.665 ; one-sided $\mathrm{p}<0.0001$ ). The ORR with axitinib was also superior, at $19.4 \%$, compared with an ORR of $9.4 \%$ with sorafenib. Axitinib is currently under review by FDA.

\subsection{Tivozanib (AV-951)}

Tivozanib is another potent and selective oral inhibitor of VEGFR 1, 2, and 3 kinases. In a randomized phase II discontinuation trial, tivozanib was administered at a dose of $1.5 \mathrm{mg}$ /day every 4 weeks ( 3 weeks on and one week off). An overall response rate of $27 \%$ and median progression-free survival rate of 11.8 months was reported with the greatest benefit in patients with clear cell component who had undergone nephrectomy on subgroup analysis (ORR of 32\% and median PFS of 14.8 months) (Bhargava et al., 2010). The treatment was well tolerated; hypertension and dysphonia were the most frequent adverse events $(54.4 \%$ and $21 \%$ respectively). This led to a global phase III clinical trial, TIVO-1 to evaluate the efficacy of tivozanib compared with sorafenib in patients with advanced RCC. The results of this study are awaited. 


\subsection{Other Novel Agents under Investigation}

\subsubsection{Dovitinib (TKI258)}

Dovitinib (TKI258) is an oral inhibitor of VEGFR and fibroblast growth factor receptors (FGFR). A recent phase II study ( $\mathrm{n}=59$ ) showed PFS and OS of 6.1 and 16 months respectively (Angevin, 2011). Stable disease ( $\geq 4$ months) was seen in $19(37 \%)$ and partial response in $4(8 \%)$ patients. In patients who previously progressed on VEGFR and mTOR inhibitors $(\mathrm{n}=31)$, median PFS and OS were 6.1 and 10.2 months respectively. The most common side effects were nausea, vomiting, diarrhea and fatigue. A randomized phase III trial to compare the efficacy of dovitinib and sorafenib as third-line treatment in metastatic RCC is planned.

\subsubsection{AMG 386}

Angiopoietins are growth factors that promote angiogenesis. AMG 386, a peptide-Fc fusion protein sequesters angiopoietin 1 and 2 thus preventing their interaction with the Tie 2 receptor on the endothelial cells which is crucial in angiogenesis. A randomized placebo-controlled phase II study showed similar PFS but higher ORR in the AMG 386 and sorafenib arm compared to sorafenib and placebo group suggestive of its antitumor effect (B. Rini, Szczylik, \& Tannir, 2011). A phase II trial in combination with sunitinib in first line or after cytokine failure is currently active.

\subsubsection{Ramucirumab (IMC-1121B)}

Ramicirumab is a fully human immunoglobulin G1 monoclonal antibody that binds VEGFR-2 and blocks VEGF binding thereby inhibiting angiogenesis. Patients who progressed on or were intolerant to sorafenib, sunitinib or both were evaluated in a phase II study ( $\mathrm{n}=39$ ) (J. Garcia et al., 2010). Two patients had confirmed partial responses and 19 patients (49\%) had stable disease lasting more than 5 months. Preliminary reports showed an encouraging PFS of 6 months. The clinical activity observed warrants further studies.

\subsubsection{Aflibercept or VEGF-TRAP (AVE0005)}

Vascular endothelial growth factor (VEGF) Trap (aflibercept) is an angiogenesis inhibitor comprising portions of the extracellular domains of human VEGF receptors 1 and 2 fused to the $\mathrm{Fc}$ portion of human immunoglobulin G. It showed significant inhibition of tumor growth and angiogenesis in murine model of RCC (Verheul et al., 2007). A phase II study is comparing two different dosing regimens of the drug.

\subsubsection{Vorinostat}

Histone deacetylase (HDAC) inhibitors inhibit hypoxia inducible factor and in combination with VEGF inhibiting agents have antitumor effect. A phase II study tested the combination of vorinostat and bevacizumab in patients with prior progression on TKI or mTOR inhibitor or cytokine based therapy. Of 32 evaluable patients, 6 patients had objective responses (18\%) including one complete response and 5 partial responses. Nineteen (67\%) patients had stable disease. The median PFS and OS were 5.3 and 16.2 months respectively (Pili et al., 2010).

Development of new therapeutic agents and formulating methods to stratify which patients would benefit from them could translate into major advancements in the treatment of patients with advanced renal cell carcinoma.

\subsection{Ongoing Trials to Determine Treatment Algorithm}

With rapid addition of new treatment options for advanced renal cell carcinoma, the optimal treatment algorithm is a challenge. There are not many randomized trials which compared the efficacy of the currently available agents to further improve the patient outcomes. One such study is the COMPARZ trial (NCT00720941) which is a phase III trial comparing pazopanib to sunitinib as first line therapy in clear-cell locally advanced or metastatic RCC. ${ }^{4}$ Primary outcome measure is the progression free survival. The trial has completed accrual and results are awaited.

There are several ongoing trials which might help in optimizing the sequence of therapy considering that most patients with advanced or metastatic RCC eventually progress and require further lines of therapy to help control the disease. RECORD-3 trial is an open-label multicenter phase II study to compare the efficacy of everolimus as first line treatment followed by sunitinib with sunitinib as first-line therapy followed by everolimus on progression of the disease (NCT00903175). Another international randomized open-label trial will compare the efficacy of temsirolimus and sorafenib when used as second line setting in patients with advanced RCC who progressed on first line treatment with sunitinib (NCT00474786). Another interesting study, START (Sequential Two-Agent Assessment in Renal Cell Carcinoma Therapy) trial will compare six different drug sequences of everolimus, pazopanib and bevacizumab in previously untreated patients (NCT01217931). ${ }^{7}$ On evidence of disease progression in patients randomized to any of the three agents, the patients will be re-randomized to the 
remaining two agents. The study will help to determine the tolerability of the two-drug sequence and overall time to progression in the various sequences.

Another area of active research is the optimum combination of therapies for metastatic renal cell carcinoma. Combining available established therapies may or may not increase the response rate at the expense of increased toxicity (Feldman et al., 2009; Sosman et al., 2006; Negrier et al., 2011). Combination of VEGF and mTOR inhibition is currently being tested in two trials. INTORACT (Investigation of Torisel and Avastin Combination Therapy) is an international randomized, phase III open label study comparing PFS among patients treated with bevacizumab plus temsirolimus to those treated with bevacizumab plus interferon alpha as first line treatment. RECORD-2, a phase II trial will compare PFS among patients treated with bevacizumab plus everolimus versus bevacizumab plus IFN- $\alpha$ as first line treatment.

\section{Conclusion}

The advent of targeted therapy has improved the outlook of metastatic renal cell carcinoma providing multitude of options to patients along with improved response rates, better tolerability, improved quality of life and prolongation of survival. The drugs approved have mostly been able to prolong progression- free survival and improve overall survival in the case of temsirolimus. Despite all the progress, interleukin-2 remains the only drug to date that is able to provide long term durable response in a small subset of patients. The task for the future is daunting if not difficult as investigators have the task of identifying subsets of patients that would respond optimally to certain treatments with minimal toxicities. The identification of biomarkers that would predict response and prognosis may be of utmost importance. Genomic expression and proteomic profiling of tissue from patients with metastatic RCC may emerge as potential strategies to optimize patient selection for specific targeted therapies though combining the technologies can be complicated.

\section{References}

Alexandrescu, D. T., McClure, R., Farzanmehr, H., \& Dasanu, C. A. (2008). Secondary erythrocytosis produced by the tyrosine kinase inhibitors sunitinib and sorafenib. $J$ Clin Oncol, 26(24), 4047-4048. http://dx.doi.org/10.1200/JCO.2008.18.3525

Amato, R. J., Jac, J., Giessinger, S., Saxena, S., \& Willis, J. P. (2009). A phase 2 study with a daily regimen of the oral mTOR inhibitor RAD001 (everolimus) in patients with metastatic clear cell renal cell cancer. Cancer, 115(11), 2438-2446. http://dx.doi.org/10.1002/cncr.24280

Angevin, E., Grünwald, V., Ravaud, A., Castellano, D. E., Lin, C. C., Gschwend, J. E., ... Escudier, B. J. (2011). A phase II study of dovitinib (TKI258), an FGFR- and VEGFR-inhibitor, in patients with advanced or metastatic renal cell cancer (mRCC). [Abstract]. J Clin Oncol, 29(2011 (suppl; abstr 4551) ).

Atkins, M. B., Hidalgo, M., Stadler, W. M., Logan, T. F., Dutcher, J. P., Hudes, G. R., et al. (2004). Randomized phase II study of multiple dose levels of CCI-779, a novel mammalian target of rapamycin kinase inhibitor, in patients with advanced refractory renal cell carcinoma. $J$ Clin Oncol, 22(5), 909-918. http://dx.doi.org/10.1200/JCO.2004.08.185

Barrios, C. H., Hernandez-Barajas, D., Brown, M. P., Lee, S. H., Fein, L., Liu, J. H., et al. (2011). Phase II trial of continuous once-daily dosing of sunitinib as first-line treatment in patients with metastatic renal cell carcinoma. Cancer.

Bleumer, I., Oosterwijk, E., De Mulder, P., \& Mulders, P. F. (2003). Immunotherapy for renal cell carcinoma. Eur Urol, 44(1), 65-75. http://dx.doi.org/10.1016/S0302-2838(03)00191-X

Bono, P., Elfving, H., Utriainen, T., Osterlund, P., Saarto, T., Alanko, T., et al. (2009). Hypertension and clinical benefit of bevacizumab in the treatment of advanced renal cell carcinoma. Ann Oncol, 20(2), 393-394. http://dx.doi.org/10.1093/annonc/mdn729

Brugarolas, J. (2007). Renal-cell carcinoma--molecular pathways and therapies. N Engl J Med, 356(2), 185-187. http://dx.doi.org/10.1056/NEJMe068263

Bui, M. H., Seligson, D., Han, K. R., Pantuck, A. J., Dorey, F. J., Huang, Y., et al. (2003). Carbonic anhydrase IX is an independent predictor of survival in advanced renal clear cell carcinoma: implications for prognosis and therapy. Clin Cancer Res, 9(2), 802-811.

Busch, J., Seidel, C., Kempkensteffen, C., Johannsen, M., Wolff, I., Hinz, S., et al. (2011). Sequence therapy in patients with metastatic renal cell carcinoma: comparison of common targeted treatment options following failure of receptor tyrosine kinase inhibitors. Eur Urol, 60(6), 1163-1170. http://dx.doi.org/10.1016/j.eururo.2011.07.037 
Chiche, J., Ilc, K., Laferriere, J., Trottier, E., Dayan, F., Mazure, N. M., et al. (2009). Hypoxia-inducible carbonic anhydrase IX and XII promote tumor cell growth by counteracting acidosis through the regulation of the intracellular pH. Cancer Res, 69(1), 358-368. http://dx.doi.org/10.1158/0008-5472.CAN-08-2470

Desai, J., Yassa, L., Marqusee, E., George, S., Frates, M. C., Chen, M. H., et al. (2006). Hypothyroidism after sunitinib treatment for patients with gastrointestinal stromal tumors. Ann Intern Med, 145(9), 660-664.

Di Lorenzo, G., Buonerba, C., Federico, P., Rescigno, P., Milella, M., Ortega, C., et al. (2010). Third-line sorafenib after sequential therapy with sunitinib and mTOR inhibitors in metastatic renal cell carcinoma. Eur Urol, 58(6), 906-911. http://dx.doi.org/10.1016/j.eururo.2010.09.008

Di Lorenzo, G., Porta, C., Bellmunt, J., Sternberg, C., Kirkali, Z., Staehler, M., et al. (2011). Toxicities of targeted therapy and their management in kidney cancer. Eur Urol, 59(4), 526-540. http://dx.doi.org/10.1016/j.eururo.2011.01.002

Dudek, A. Z., Zolnierek, J., Dham, A., Lindgren, B. R., \& Szczylik, C. (2009). Sequential therapy with sorafenib and sunitinib in renal cell carcinoma. Cancer, 115(1), 61-67. http://dx.doi.org/10.1002/cncr.24009

Escudier, B., Bellmunt, J., Negrier, S., Bajetta, E., Melichar, B., Bracarda, S., et al. (2010). Phase III trial of bevacizumab plus interferon alfa-2a in patients with metastatic renal cell carcinoma (AVOREN): final analysis of overall survival. J Clin Oncol, 28(13), 2144-2150. http://dx.doi.org/10.1200/JCO.2009.26.7849

Escudier, B., Chevreau, C., Lasset, C., Douillard, J. Y., Ravaud, A., Fabbro, M., et al. (1999). Cytokines in metastatic renal cell carcinoma: is it useful to switch to interleukin-2 or interferon after failure of a first treatment? Groupe Francais d'Immunotherape. J Clin Oncol, 17(7), 2039-2043.

Escudier, B., Eisen, T., Stadler, W. M., Szczylik, C., Oudard, S., Siebels, M., et al. (2007). Sorafenib in advanced clear-cell renal-cell carcinoma. $N$ Engl J Med, 356(2), 125-134. http://dx.doi.org/10.1056/NEJM oa060655

Escudier, B., Eisen, T., Stadler, W. M., Szczylik, C., Oudard, S., Staehler, M., et al. (2009). Sorafenib for treatment of renal cell carcinoma: Final efficacy and safety results of the phase III treatment approaches in renal cancer global evaluation trial. J Clin Oncol, 27(20), 3312-3318. http://dx.doi.org/10.1200/JCO.2008. 19.5511

Escudier, B., Roigas, J., Gillessen, S., Harmenberg, U., Srinivas, S., Mulder, S. F., et al. (2009). Phase II study of sunitinib administered in a continuous once-daily dosing regimen in patients with cytokine-refractory metastatic renal cell carcinoma. J Clin Oncol, 27(25), 4068-4075. http://dx.doi.org/10.1200/JCO.2008.20. 5476

Escudier, B., Szczylik, C., Hutson, T. E., Demkow, T., Staehler, M., Rolland, F., et al. (2009). Randomized phase II trial of first-line treatment with sorafenib versus interferon Alfa-2a in patients with metastatic renal cell carcinoma. J Clin Oncol, 27(8), 1280-1289. http://dx.doi.org/10.1200/JCO.2008.19.3342

Feldman, D. R., Baum, M. S., Ginsberg, M. S., Hassoun, H., Flombaum, C. D., Velasco, S., et al. (2009). Phase I trial of bevacizumab plus escalated doses of sunitinib in patients with metastatic renal cell carcinoma. $J$ Clin Oncol, 27(9), 1432-1439. http://dx.doi.org/10.1200/JCO.2008.19.0108

Garcia, J., Hudes, G., Choueiri, T., Stadler, W., Wood, L., Bhatia, S., et al. (2010). Phase II study of IMC-1121B in patients with metastatic renal cancer (mRCC) following VEGFR-2 tyrosine kinase inhibitor (TKI) therapy (IMCL CP12-0605/NCT00515697).

Garcia, J. A., Hutson, T. E., Elson, P., Cowey, C. L., Gilligan, T., Nemec, C., et al. (2010). Sorafenib in patients with metastatic renal cell carcinoma refractory to either sunitinib or bevacizumab. Cancer, 116(23), 5383-5390. http://dx.doi.org/10.1002/cncr.25327

Gleave, M. E., Elhilali, M., Fradet, Y., Davis, I., Venner, P., Saad, F., et al. (1998). Interferon gamma-1b compared with placebo in metastatic renal-cell carcinoma. Canadian Urologic Oncology Group. $N$ Engl $J$ Med, 338(18), 1265-1271. http://dx.doi.org/10.1056/NEJM199804303381804

Gnarra, J. R., Tory, K., Weng, Y., Schmidt, L., Wei, M. H., Li, H., et al. (1994). Mutations of the VHL tumour suppressor gene in renal carcinoma. Nat Genet, 7(1), 85-90. http://dx.doi.org/10.1038/ng0594-85

Grunwald, V., Weikert, S., Seidel, C., Busch, J., Johannsen, A., Fenner, M., et al. (2011). Efficacy of sunitinib re-exposure after failure of an mTOR inhibitor in patients with metastatic RCC. Onkologie, 34(6), 310-314. http://dx.doi.org/10.1159/000328575 
Hapani, S., Chu, D., \& Wu, S. (2009). Risk of gastrointestinal perforation in patients with cancer treated with bevacizumab: a meta-analysis. Lancet Oncol, 10(6), 559-568. http://dx.doi.org/10.1016/S1470-2045(09)70 $112-3$

Hudes, G., Carducci, M., Tomczak, P., Dutcher, J., Figlin, R., Kapoor, A., et al. (2007). Temsirolimus, interferon alfa, or both for advanced renal-cell carcinoma. $N$ Engl J Med, 356(22), 2271-2281. http://dx.doi.org/10.10 56/NEJMoa066838

Hudson, C. C., Liu, M., Chiang, G. G., Otterness, D. M., Loomis, D. C., Kaper, F., et al. (2002). Regulation of hypoxia-inducible factor 1alpha expression and function by the mammalian target of rapamycin. Mol Cell Biol, 22(20), 7004-7014. http://dx.doi.org/10.1128/MCB.22.20.7004-7014.2002

Hutson, T. E., Davis, I. D., Machiels, J. P., De Souza, P. L., Rottey, S., Hong, B. F., et al. (2010). Efficacy and safety of pazopanib in patients with metastatic renal cell carcinoma. J Clin Oncol, 28(3), 475-480. http://dx.doi.org/10.1200/JCO.2008.21.6994

Jacobsen, J., Grankvist, K., Rasmuson, T., Bergh, A., Landberg, G., \& Ljungberg, B. (2004). Expression of vascular endothelial growth factor protein in human renal cell carcinoma. BJU Int, 93(3), 297-302. http://dx.doi.org/10.1111/j.1464-410X.2004.04605.x

Jemal, A., Siegel, R., Xu, J., \& Ward, E. (2010). Cancer statistics, 2010. CA Cancer J Clin, 60(5), 277-300. http://dx.doi.org/10.3322/caac.20073

Karaman, M. W., Herrgard, S., Treiber, D. K., Gallant, P., Atteridge, C. E., Campbell, B. T., et al. (2008). A quantitative analysis of kinase inhibitor selectivity. Nat Biotechnol, 26(1), 127-132. http://dx.doi.org/10.1038/nbt1358

Kim, W. Y., \& Kaelin, W. G. (2004). Role of VHL gene mutation in human cancer. J Clin Oncol, 22(24), 4991-5004. http://dx.doi.org/10.1200/JCO.2004.05.061

Liu, X., Powlas, J., Shi, Y., Oleksijew, A. X., Shoemaker, A. R., De Jong, R., et al. (2004). Rapamycin inhibits Akt-mediated oncogenic transformation and tumor growth. Anticancer Res, 24(5A), 2697-2704.

Mackenzie, M. J., Rini, B. I., Elson, P., Schwandt, A., Wood, L., Trinkhaus, M., et al. (2011). Temsirolimus in VEGF-refractory metastatic renal cell carcinoma. Ann Oncol, 22(1), 145-148. http://dx.doi.org/10.1093/an nonc/mdq320

Maroto, J. P., Hudes, G., Dutcher, J. P., Logan, T. F., White, C. S., Krygowski, M., et al. (2011). Drug-related pneumonitis in patients with advanced renal cell carcinoma treated with temsirolimus. J Clin Oncol, 29(13), 1750-1756. http://dx.doi.org/10.1200/JCO.2010.29.2235

McDermott, D. F., Regan, M. M., Clark, J. I., Flaherty, L. E., Weiss, G. R., Logan, T. F., et al. (2005). Randomized phase III trial of high-dose interleukin-2 versus subcutaneous interleukin-2 and interferon in patients with metastatic renal cell carcinoma. J Clin Oncol, 23(1), 133-141. http://dx.doi.org/10.1200/JCO. 2005.03.206

Melichar, B., Koralewski, P., Ravaud, A., Pluzanska, A., Bracarda, S., Szczylik, C., et al. (2008). First-line bevacizumab combined with reduced dose interferon-alpha2a is active in patients with metastatic renal cell carcinoma. Ann Oncol, 19(8), 1470-1476. http://dx.doi.org/10.1093/annonc/mdn161 PMid: 18408224

Moch, H., Gasser, T., Amin, M. B., Torhorst, J., Sauter, G., \& Mihatsch, M. J. (2000). Prognostic utility of the recently recommended histologic classification and revised TNM staging system of renal cell carcinoma: a Swiss experience with 588 tumors. Cancer, 89(3), 604-614. http://dx.doi.org/10.1002/1097-0142(2000080 1)89:3<604::AID-CNCR16>3.0.CO;2-Q

Motzer, R., Hutson, T., Olsen, M., Hudes, G., Burke, J., \& Edenfield, W. (2011). Randomized phase II multicenter study of the efficacy and safety of sunitinib on the $4 / 2$ versus continuous dosing schedule as first-line therapy of metastatic renal cell carcinoma: Renal EFFECT Trial. J Clin Oncol, 29(Suppl 7).

Motzer, R. J., Bacik, J., Murphy, B. A., Russo, P., \& Mazumdar, M. (2002). Interferon-alfa as a comparative treatment for clinical trials of new therapies against advanced renal cell carcinoma. J Clin Oncol, 20(1), 289-296. http://dx.doi.org/10.1200/JCO.20.1.289

Motzer, R. J., Escudier, B., Oudard, S., Hutson, T. E., Porta, C., Bracarda, S., et al. (2010). Phase 3 trial of everolimus for metastatic renal cell carcinoma : final results and analysis of prognostic factors. Cancer, 116(18), 4256-4265. http://dx.doi.org/10.1002/cncr.25219 
Motzer, R. J., Escudier, B., Oudard, S., Hutson, T. E., Porta, C., Bracarda, S., et al. (2008). Efficacy of everolimus in advanced renal cell carcinoma: a double-blind, randomised, placebo-controlled phase III trial. Lancet, 372(9637), 449-456. http://dx.doi.org/10.1016/S0140-6736(08)61039-9

Motzer, R. J., Hutson, T. E., Tomczak, P., Michaelson, M. D., Bukowski, R. M., Oudard, S., et al. (2009). Overall survival and updated results for sunitinib compared with interferon alfa in patients with metastatic renal cell carcinoma. J Clin Oncol, 27(22), 3584-3590. http://dx.doi.org/10.1200/JCO.2008.20.1293

Motzer, R. J., Hutson, T. E., Tomczak, P., Michaelson, M. D., Bukowski, R. M., Rixe, O., et al. (2007). Sunitinib versus interferon alfa in metastatic renal-cell carcinoma. $N$ Engl $J$ Med, 356(2), 115-124. http://dx.doi.org/10.1056/NEJMoa065044

Motzer, R. J., Mazumdar, M., Bacik, J., Berg, W., Amsterdam, A., \& Ferrara, J. (1999). Survival and prognostic stratification of 670 patients with advanced renal cell carcinoma. J Clin Oncol, 17(8), 2530-2540.

Motzer, R. J., Michaelson, M. D., Redman, B. G., Hudes, G. R., Wilding, G., Figlin, R. A., et al. (2006). Activity of SU11248, a multitargeted inhibitor of vascular endothelial growth factor receptor and platelet-derived growth factor receptor, in patients with metastatic renal cell carcinoma. J Clin Oncol, 24(1), 16-24. http://dx.doi.org/10.1200/JCO.2005.02.2574

Motzer, R. J., Rini, B. I., Bukowski, R. M., Curti, B. D., George, D. J., Hudes, G. R., et al. (2006). Sunitinib in patients with metastatic renal cell carcinoma. JAMA, 295(21), 2516-2524. http://dx.doi.org/10.1001/jama. 295.21.2516

Mulders, P. (2009). Vascular endothelial growth factor and mTOR pathways in renal cell carcinoma: differences and synergies of two targeted mechanisms. BJU Int, 104(11), 1585-1589. http://dx.doi.org/10.1111/j.1464410X.2009.08987.X

Negrier, S., Gravis, G., Perol, D., Chevreau, C., Delva, R., Bay, J. O., et al. (2011). Temsirolimus and bevacizumab, or sunitinib, or interferon alfa and bevacizumab for patients with advanced renal cell carcinoma (TORAVA): a randomised phase 2 trial. Lancet Oncol, 12(7), 673-680. http://dx.doi.org/10.1016/S1470-2045(11)70124-3

Papazisis, K. T., Kontovinis, L. F., Papandreou, C. N., Kouvatseas, G., Lafaras, C., Antonakis, E., et al. (2010). Brain natriuretic peptide precursor (NT-pro-BNP) levels predict for clinical benefit to sunitinib treatment in patients with metastatic renal cell carcinoma. BMC Cancer, 10, 489. http://dx.doi.org/10.1186/1471-2407$10-489$

Patil, S., Figlin, R. A., Hutson, T. E., Michaelson, M. D., Negrier, S., Kim, S. T., et al. (2011). Prognostic factors for progression-free and overall survival with sunitinib targeted therapy and with cytokine as first-line therapy in patients with metastatic renal cell carcinoma. Ann Oncol, 22(2), 295-300. http://dx.doi.org/10.1093/annonc/mdq342

Pena, C., Lathia, C., Shan, M., Escudier, B., \& Bukowski, R. M. (2010). Biomarkers predicting outcome in patients with advanced renal cell carcinoma: Results from sorafenib phase III Treatment Approaches in Renal Cancer Global Evaluation Trial. Clin Cancer Res, 16(19), 4853-4863. http://dx.doi.org/10.1158/1078-0432.CCR-09-3343

Pili, R., Lodge, M., Verheul, H., Mashtare, T., Wahl, R., Martin, J., et al. (2010). Combination of the histone deacetylase inhibitor vorinostat with bevacizumab in pretreated patients with renal cell carcinoma: safety, efficacy, and pharmacodynamic results.

Porta, C., Procopio, G., Carteni, G., Sabbatini, R., Bearz, A., Chiappino, I., et al. (2011). Sequential use of sorafenib and sunitinib in advanced renal-cell carcinoma (RCC): an Italian multicentre retrospective analysis of 189 patient cases. BJU Int, 108(8 Pt 2), E250-257. http://dx.doi.org/10.1111/j.1464-410X.2011. 10186.x

Ratain, M. J., Eisen, T., Stadler, W. M., Flaherty, K. T., Kaye, S. B., Rosner, G. L., et al. (2006). Phase II placebo-controlled randomized discontinuation trial of sorafenib in patients with metastatic renal cell carcinoma. J Clin Oncol, 24(16), 2505-2512. http://dx.doi.org/10.1200/JCO.2005.03.6723

Reeves, J., Spigel, D., Daniel, D., Friedman, E., Burris, H., \& Hainsworth, J. (2011). Pazopanib in patients with metastatic renal cell carcinoma previously treated with sunitinib or bevacizumab: a Sarah Cannon Research Institute phase II trial. [Abstract]. J Clin Oncol, 29:2011(suppl; abstr 4659 ). 
Rini, B., Szczylik, C., \& Tannir, N. (2011). AMG 386 in combination with sorafenib in patients (pts) with metastatic renal cell cancer (mRCC): a randomized, double-blind, placebo-controlled, phase II study. J Clin Oncol, 29: 2011 (suppl 7; abstr 309).

Rini, B. I. (2010). New strategies in kidney cancer: therapeutic advances through understanding the molecular basis of response and resistance. Clin Cancer Res, 16(5), 1348-1354. http://dx.doi.org/10.1158/1078-0432.CCR-09-2273

Rini, B. I., Cohen, D. P., Lu, D. R., Chen, I., Hariharan, S., Gore, M. E., et al. (2011). Hypertension as a biomarker of efficacy in patients with metastatic renal cell carcinoma treated with sunitinib. $J$ Natl Cancer Inst, 103(9), 763-773. http://dx.doi.org/10.1093/jnci/djr128

Rini, B. I., Escudier, B., Tomczak, P., Kaprin, A., Szczylik, C., Hutson, T. E., et al. (2011). Comparative effectiveness of axitinib versus sorafenib in advanced renal cell carcinoma (AXIS): a randomised phase 3 trial. Lancet, 378(9807), 1931-1939. http://dx.doi.org/10.1016/S0140-6736(11)61613-9

Rini, B. I., Halabi, S., Rosenberg, J. E., Stadler, W. M., Vaena, D. A., Archer, L., et al. (2010). Phase III trial of bevacizumab plus interferon alfa versus interferon alfa monotherapy in patients with metastatic renal cell carcinoma: final results of CALGB 90206. J Clin Oncol, 28(13), 2137-2143. http://dx.doi.org/10.1200/JCO.2009.26.5561

Rini, B. I., Michaelson, M. D., Rosenberg, J. E., Bukowski, R. M., Sosman, J. A., Stadler, W. M., et al. (2008). Antitumor activity and biomarker analysis of sunitinib in patients with bevacizumab-refractory metastatic renal cell carcinoma. J Clin Oncol, 26(22), 3743-3748. http://dx.doi.org/10.1200/JCO.2007.15.5416

Rini, B. I., Tamaskar, I., Shaheen, P., Salas, R., Garcia, J., Wood, L., et al. (2007). Hypothyroidism in patients with metastatic renal cell carcinoma treated with sunitinib. J Natl Cancer Inst, 99(1), 81-83. http://dx.doi.org/10.1093/jnci/djk008

Robert, C., Mateus, C., Spatz, A., Wechsler, J., \& Escudier, B. (2009). Dermatologic symptoms associated with the multikinase inhibitor sorafenib. J Am Acad Dermatol, 60(2), 299-305. http://dx.doi.org/10.1016/j.jaad.2008.06.034

Sablin, M. P., Negrier, S., Ravaud, A., Oudard, S., Balleyguier, C., Gautier, J., et al. (2009). Sequential sorafenib and sunitinib for renal cell carcinoma. $J$ Urol, 182(1), 29-34; discussion 34 . http://dx.doi.org/10.1016/j.juro.2009.02.119

Scartozzi, M., Galizia, E., Chiorrini, S., Giampieri, R., Berardi, R., Pierantoni, C., et al. (2009). Arterial hypertension correlates with clinical outcome in colorectal cancer patients treated with first-line bevacizumab. Ann Oncol, 20(2), 227-230. http://dx.doi.org/10.1093/annonc/mdn637

Shin Lee, J., Seok Kim, H., Bok Kim, Y., Cheol Lee, M., \& Soo Park, C. (2003). Expression of PTEN in renal cell carcinoma and its relation to tumor behavior and growth. J Surg Oncol, 84(3), 166-172. http://dx.doi.org/10.1002/jso.10302

Skillings, J., Johnson, D., Miller, K., Kabbinavar, F., Bergsland, E., Holmgren, E., et al. (2005). Arterial thromboembolic events (ATEs) in a pooled analysis of 5 randomized, controlled trials (RCTs) of bevacizumab (BV) with chemotherapy. Journal of Clinical Oncology, 23(16_suppl), 3019.

Sosman, J., Flaherty, K., Atkins, M., Puzanov, I., McDermott, D., Vermeulen, W., et al. (2006). A phase I/II trial of sorafenib (S) with bevacizumab (B) in metastatic renal cell cancer (mRCC) patients (Pts). Journal of Clinical Oncology, 24(18_suppl), 3031.

Sternberg, C. N., Davis, I. D., Mardiak, J., Szczylik, C., Lee, E., Wagstaff, J., et al. (2010). Pazopanib in locally advanced or metastatic renal cell carcinoma: results of a randomized phase III trial. J Clin Oncol, 28(6), 1061-1068. http://dx.doi.org/10.1200/JCO.2009.23.9764

Surks, M. I., Ortiz, E., Daniels, G. H., Sawin, C. T., Col, N. F., Cobin, R. H., et al. (2004). Subclinical thyroid disease: scientific review and guidelines for diagnosis and management. JAMA, 291(2), 228-238. http://dx.doi.org/10.1001/jama.291.2.228

Tam, B. Y., Wei, K., Rudge, J. S., Hoffman, J., Holash, J., Park, S. K., et al. (2006). VEGF modulates erythropoiesis through regulation of adult hepatic erythropoietin synthesis. Nat Med, 12(7), 793-800. http://dx.doi.org/10.1038/nm1428 
Torino, F., Corsello, S. M., Longo, R., Barnabei, A., \& Gasparini, G. (2009). Hypothyroidism related to tyrosine kinase inhibitors: an emerging toxic effect of targeted therapy. Nat Rev Clin Oncol, 6(4), 219-228. http://dx.doi.org/10.1038/nrclinonc.2009.4

Tsui, K. H., Shvarts, O., Smith, R. B., Figlin, R., de Kernion, J. B., \& Belldegrun, A. (2000). Renal cell carcinoma: prognostic significance of incidentally detected tumors. J Urol, 163(2), 426-430. http://dx.doi.org/10.1016/S0022-5347(05)67892-5

Verheul, H. M., Hammers, H., van Erp, K., Wei, Y., Sanni, T., Salumbides, B., et al. (2007). Vascular endothelial growth factor trap blocks tumor growth, metastasis formation, and vascular leakage in an orthotopic murine renal cell cancer model. Clin Cancer Res, 13(14), 4201-4208. http://dx.doi.org/10.1158/1078-0432.CCR-06-2553

White, D. A., Camus, P., Endo, M., Escudier, B., Calvo, E., Akaza, H., et al. (2010). Noninfectious pneumonitis after everolimus therapy for advanced renal cell carcinoma. Am J Respir Crit Care Med, 182(3), 396-403. http://dx.doi.org/10.1164/rccm.200911-17200C

Wirth, M. P. (1993). Immunotherapy for metastatic renal cell carcinoma. Urol Clin North Am, 20(2), 283-295.

Wong, E., Rosen, L. S., Mulay, M., Vanvugt, A., Dinolfo, M., Tomoda, C., et al. (2007). Sunitinib induces hypothyroidism in advanced cancer patients and may inhibit thyroid peroxidase activity. Thyroid, 17(4), 351-355. http://dx.doi.org/10.1089/thy.2006.0308

Yang, J. C., Haworth, L., Sherry, R. M., Hwu, P., Schwartzentruber, D. J., Topalian, S. L., et al. (2003). A randomized trial of bevacizumab, an anti-vascular endothelial growth factor antibody, for metastatic renal cancer. $N$ Engl J Med, 349(5), 427-434. http://dx.doi.org/10.1056/NEJMoa021491

Yang, J. C., Sherry, R. M., Steinberg, S. M., Topalian, S. L., Schwartzentruber, D. J., Hwu, P., et al. (2003). Randomized study of high-dose and low-dose interleukin-2 in patients with metastatic renal cancer. $J$ Clin Oncol, 21(16), 3127-3132. http://dx.doi.org/10.1200/JCO.2003.02.122

Zhang, H. L., Zhu, Y., Wang, C. F., Yao, X. D., Zhang, S. L., Dai, B., et al. (2011). Erythrocyte sedimentation rate kinetics as a marker of treatment response and predictor of prognosis in Chinese metastatic renal cell carcinoma patients treated with sorafenib. Int $J$ Urol, 18(6), 422-430. http://dx.doi.org/10.1111/j.1442-2042.2011.02761.x

\section{Clinicaltrials.gov}

NCT01030783 A study to compare Tivozanib (AV-951) to Sorafenib in subjects with advanced renal cell carcinoma (TIVO-1). ClinicalTrials.gov. Retrieved January 16, 2012 from http://clinicaltrials.gov/ct2/show/ NCT01030783?term $=$ tivo\&rank $=1$

NCT01223027 Study of Dovitinib versus Sorafenib in patients with metastatic renal cell carcinoma. Clinicaltrials.gov. http://clinicaltrials.gov/ct2/show/NCT01223027?term=tki $+258+$ sorafenib\&rank $=2$

NCT00357760 VEGF Trap in treating patients with metastatic or unresectable kidney cancer. Clinicaltrials.gov. http://clinicaltrials.gov/ct2/show/NCT00357760?term=aflibercept+renal+cell+carcinoma\&rank=1

NCT00720941 Pazopanib versus Sunitinib in the Treatment of Locally Advanced and/or Metastatic Renal cell carcinoma (COMPARZ). Clinical Trials. gov. http://clinicaltrials.gov/ct2/show/NCT00720941?term=comp arz\&rank=1

NCT00903175 Efficacy and Safety Comparison of RAD-001 versus Sunitinib in the First-line and Second-line treatment of patients with Metastatic Renal cell carcinoma (RECORD-3). ClinicalTrials.gov. http://clinicaltrials.gov/ct2/show/NCT00903175?term=record-3\&rank=1

NCT00474786 Temsirolimus versus Sorafenib as Second-line therapy in patients with advanced RCC who have failed first-line Sunitinib. Clinical Trials. gov. http://clinicaltrials.gov/ct2/show/NCT00474786?term=nct00 474786\&rank=1

NCT 01217931 Sequential Two-agent Assessment in renal cell carcinoma therapy. ClinicalTrials.gov. Retrieved January 16, 2012 from http://clinicaltrials.gov/ct2/show/NCT01217931?term=nct01217931\&rank=1 